\title{
Addiction and the Use of Illicit Drug Use-The Oral And Dental Effects
}

\author{
*William J Maloney, DDS \\ Clinical Associate Professor, New York University, USA
}

Received: May 25, 2018; Published: May 30, 2018

*Corresponding author: William J Maloney, DDS, Clinical Associate Professor, New York University, USA

\begin{abstract}
The power of addiction must never be underestimated. Addiction is the key element in an individual's seeking and use of illicit drugs despite the knowledge of the potential harmful consequences. The dentist must be aware of the many oral and dental manifestations of the use of various drugs. Also, the dentist must be aware of the potential systemic manifestations of drugs such as heroin, cannabis, methamphetamines and cocaine in order to make the proper modifications to ensure the safe and effective delivery of dental treatment.
\end{abstract}

\section{Introduction}

Safe and effective dental treatment is the goal of all dental professionals. In order to provide this treatment, the dentist must first assess the medical status of the patient. For those patients who state a history of illicit drug use, the dentist must continue to provide an assessment of the patient's drug use and the effect it may be having on the dental and oral health of the individual and whether it is possible to obtain a proper informed consent at the present time. The dentist must then determine if modifications to the usual course of dental treatment are needed.

\section{Heroin}

Heroin is a highly addictive, illegal drug. It is processed from the resin of poppy plants. Heroin was first manufactured in 1898 as a treatment for tuberculosis and morphine addiction [1]. Heroin use has many consequences for oral health such as an increased incidence of dental caries and periodontal disease. The dentist needs to be aware that there are a number of systemic manifestations of heroin use. Psychiatric and physical signs and symptoms include euphoria, dissociation, hallucinations, track marks, sedation, delusions and slurred speech. The use of heroin and the concurrent treatment with other CNS depressant drugs present the risk of respiratory depression, hypotension, coma and profound sedation. CNS depressant drugs include benzodiazepines, barbiturates, MAO inhibitors, tricyclic antidepressants, antihistamines, general anesthetics and hypnotics. Long-term effects of heroin use include addiction, collapsed veins, abscesses, rheumatologic problems, liver disease, kidney disease, bacterial infections, and infection of the lin ing and valves of the heart. The oral and dental signs and symptoms of heroin use include rampant caries, missing teeth, periodontal disease and xerostomia [2]. Xerostomia, along with poor oral hygiene and bad diet, lead to the high incidence of caries, which are seen especially on the smooth and cervical surfaces of the teeth. Periodontal disease is more prevalent in the heroin abuser than in nonusers. It is believed that altered microbial flora exist in patients with salivary hypofunction. Heroin use may make it more difficult to achieve profound local anesthesia. This can make successful treatment more challenging. It is important to realize that the heroin-abusing patient may be seen at the dental office at different stages of his or her drug use; therefore, the practitioner needs a keen awareness of signs and symptoms of a patient in drug crisis [2].

Also of importance to the dentist is the increased incidence of periodontal disease, oral fungal infections, oral viral infections, and hyper pigmentation of the tongue. As the primary oral effect of heroin use is dental decay, the dentist must be aware of this and incorporate measures such as more frequent recall appointments and constant reinforcements of oral hygiene with the patient. Studies have demonstrated a decline in periodontal health with the duration of drug use. The cause of this is multifactorial. There are local contributing factors such as poor oral hygiene, the presence of bacteria and dental calculus. The noxious substances of heroin contribute to the damage of oral tissues as well as causing disorders of the endocrine system which may alter negatively the reaction of the periodontium to the drug stimulus leading to the destruction of the periodontium.

\section{Marijuana}

Marrijuana is a mind-altering drug which is produced by the Cannabis sativa plant. Delta-9-tetrahydrocannabinol (TCH) is the 
main psychoactive ingredient. Marijuana has many street names including Aunt Mary, Yerba, BC Bud, Weed, Blunts, Smoke, Boom, Skunk, Chronic, Dope, Reefer, Pot, Mary Jane, Joint, Hydro, Hash, Grass, Ganja and Gangster [3]. Cannabis has many pharmacological effects on humans and can potentially lead to dependence and behavioral disturbances [4]. Preclinical and clinical studies indicate that the three stages of drug addiction as described by Koob and Volkow [5] are present in cannabis addiction [6]. Cannabis addiction results in a hyperactivation of the mesocorticolimbic dopaminergic reward pathway [6].

\section{Methamphetamines}

Methamphetamines are highly powerful stimulants which are very popular with abusers due to their relatively low cost and long "high" period. This "high" period consists of enhanced well-being, increased energy, heightened libido, and appetite suppression $[7,8]$. Methamphetamines are known by a variety of street names which include ice, chalk, meth, speed, fire, crystal, and glass [9]. Approximately 10.4 million Americans aged 12 or older have at one time in their life tried methamphetamines [10]. Meth mouth [9-12] is the term which has been used extensively in the scientific literature to describe the devastating, yet predictable, dental effects of methamphetamine use. The buccal smooth surfaces of the teeth and the interproximal surfaces of the anterior teeth are affected by decay in methamphetamine users $[9,11,13-20]$. Other oral findings in methamphetamine users include clenching and grinding of teeth [21], tempromandibular disorders [22], xerostomia, and poor oral hygiene [14]. The duration of action of methamphetamines is 8-12 hours [16]. However, it can last up to 24 hours [23,24]. The vasoconstrictor in the local anesthetic could place the patient at an increased risk for myocardial infarction, hypertension, cardiac dysrhythmias, and cerebrovascular accidents [22,25-28]. Therefore, a local anesthetic without vasoconstrictor should be used in such a patient if a local anesthetic is needed $[19,22,27,29,30]$. Also, caution should be used in the administration of nitrous oxide [9] and a consultation with the patient's physician should be conducted prior to prescribing any analgesics.

\section{Cocaine}

Cocaine (benzoylmethlecgonine) is an alkaloid which is extracted from the leaf of the Erythroxylon coca bush [31]. It is classified as a psychostimulant which exhibits both local anesthetic and neurotransmitter effects [32,33]. Centrally, cocaine affects adrenergic nerve endings where it blocks the re-uptake of catecholamines and potentiates [34] particularly dopamine. This results in cocaine's transient euphoric effects [35]. Locally, cocaine blocks the initiation and propagation of nerve impulses along an axon by interference with sodium permeability during depolarization [36-40]. There are many dental effects [31,32,41-45] of cocaine use. They are: gingival lesions, tempromandibular disorders, bruxism, cervical abrasion, occlusal wear, corrosion of gold dental restorations, and excessive hemorrhage after tooth extraction, increased rate of tooth decay, and increased rate of periodontal disease. Other intra-oral and craniofacial manifestations [31,32,41-46] include oral candidal infections, nasal necrosis, headaches, perforation of palate, oral ulcers, bilateral cleft lip and palate in fetus, xerostomia, angular cheilitis, halitosis, glossdynia, and erosive lichen planus. The administration of a local anesthetic with vasoconstrictor may result in an acute rise in blood pressure $[31,47]$. There is also a risk of convulsions associated with the combination of lidocaine and cocaine potentiates [31,48-51]. Use of epinephrine-impregnated retraction cords is also contraindicated [41]. It is advisable to postpone any dental treatment at least 6 to 24 hours after the use of cocaine $[31,47,49,52]$.

\section{Conclusion}

The use of illicit drugs can necessitate possible modifications to the usual course of dental treatment. Methamphetamines, heroin, cannabis and cocaine all have dental and oral manifestations of which the dentist must be cognizant in order to provide safe and effective dental treatment. The dentist must also be aware of the strong role addiction has in the compulsive behavior of the drug seeker.

\section{References}

1. Hosztafi S (2001) The history of heroin. Acta Pharm Hung 71(2): 233242.

2. Maloney WJ, Fleisher LR (2016) The Oral and Dental Significance of Heroin and its Resurgence in New York State. New York State Dental Journal 82(5): 52-54.

3. (2018) DEA. Drug Fact Sheet.

4. Sharma P, Murthy P, Srinivas Bharath MM (2012) Chemistry, metabolism and toxicology of cannabis. Clinical implications. Iran J Psychiatry Fall 7 (4): 149-156.

5. Koob GF, Volkow ND (2016) Neurobiology of addiction: a neurocircuitry analysis. Lancet Psychiatry 3(8): 760-773.

6. Zehra A, Burns J, Lin CK et al. ((2018) J Neuroimmune Pharmacol 1-15.

7. Lineberry TW, Bostwick JM (2006) Methamphetamine abuse: a perfect storm of complications. Mayo Clin Proc 81(1): 77-84.

8. (2002) National Institute on Drug Abuse. Research Report Series: Methamphetamine Abuse and Addiction. NIH Publication No. 02-4210.

9. (2018) Methamphetamine use (Meth Mouth). American Dental Association.

10. (2006) National Institute on Drug Abuse. Methamphetamine: abuse and addiction. NIH Publication Number 06-4210.

11. Shaner JW (2002) Caries associated with methamphetamine abuse. J Mich Dent Assoc 84(9): 42-47.

12. McGrath C, Chan B (2005) Oral health sensations associated with illicit drug abuse. Br Dent J 198(3): 159-162.

13. Howe AM (1995) Methamphetamine and childhood and adolescent caries. Aust Dent J 40(5): 340.

14. Morio KA, Marshall TA, Qian F, Morgan TA (2008) Comparing diet, oral hygiene and caries status of adult methamphetamine users and nonusers: a pilot study. J Am Dent Assoc 139(2): 171-176.

15. Duxbury AJ (1993) Ecstasy-dental implications. Br Dent J 175(1): 38.

16. Rhodus NL, Little JW (2005) Methampheamine abuse and "meth mouth". Northwest Dent 84(5): 29, 31, 33-37.

17. Shaner JW, Kimmes N, Saini T, Edwards P (2006) “Meth mouth"; rampant caries in methamphetamine abusers. AIDS Patient Care STDs 20(3): 146-150. 
18. Klasser GD, Epstein JB (2006) The methamphetamine epidemic and dentistry. Gen Dent 54(6): 431-439.

19. Donaldson M, Goodchild JH (2006) Oral health of the methamphetamine abuser. Am J Health Syst Pharm 63(21): 2078-2082.

20. Saini T, Edwards PC, Kimmes NS, Carroll LR, Shaner JW, et al. (2005) Etiology of xerostomia and dental caries among methamphetamine abusers. Oral Health Prev Dent 3(3):189-195.

21. Department of Justice. Meth awareness.

22. Hamamoto DT, Rhodus NL (2009) Methamphetamine abuse and dentistry. Oral Diseases 15(1): 27-37.

23. Henry JA Amphetamines. In: Ford MD, Delaney KA, Ling LJ, Erickson T (Eds.), Clinical toxicology, (1 $1^{\text {st }}$ Edn) W.B. Saunders Co.: Philadelphia, pp. 620-627.

24. O’Brien CP Drug addiction and drug abuse. In: Brunton LL, Lazo J, Parker K (Eds.), Goodman's \& Gilman's the pharmacological basis of therapeutics. (11 ${ }^{\text {th }}$ Edn) McGraw-Hill: New York, USA, pp. 1109-1186.

25. Turnispeed SD, Richards JR, Kirk JD, Diercks DB, Amsterdam EA (2003) Frequency of acute coronary syndrome in patients presenting to the emergency department with chest pains after methamphetamine use. J Emerg Med 24(4): 369-373.

26. McGee SM, McGee DN, McGee MB (2004) Spontaneous intracerebral hemorrhage related to methamphetamine abuse: autopsy findings and clinical correlation. Am J Forensic Med Pathol 25(4): 334-337.

27. Little JW, Falace DA, Miller CS, Rhodus NL (2008) In: Dental management of the medically compromised patient. ( $7^{\text {th }}$ Edn) Mosby Elsevier: St. Louis, pp. 507-532.

28. Bolla KI, Cade JL (2007) Exogenous acquired metabolic disorders of the nervous system: toxins and illicit drugs. Textbook of clinical neurology. ( $3^{\text {rd }}$ Edn) Saunders Elsevier: Philadelphia, pp. 865-896.

29. (2005) American Dental Association. For the dental patient. Methamphetamine use and oral health. J Am Dent Assoc 136: 1491.

30. Goodchild JH, Donaldson M (2007) Methamphetamine abuse and dentistry: a review of the literature and presentation of a clinical case. Quintessence Int 38(7): 583-590.

31. Brand HS, Gonggrijp S, Blanksma CJ (2008) Cocaine and oral health. British Dental Journal 204: 365-369.

32. Villa PD (1999) Midfacial complications of prolonged cocaine snort. J Can Dent Assoc 65: 218-223.

33. Goldstein FJ (1990) Toxicity of cocaine. Compendium 11(12): $710,712,714-716$.

34. Sastry RC, Lee D, Har-El G (1997) Palatal perforation from cocaine abuse. Otolaryngol Head Neck Surg 116(4): 565-566.

35. Schweitzer V (1986) Osteolytic sinusitis and pneumomediastinum: deceptive otolaryngologic complications of cocaine abuse. Laryngoscope 96(2): 206-210.

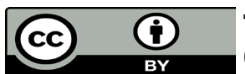

This work is licensed under Creative Commons Attribution 4.0 License

Submission Link: https://biomedres.us/submit-manuscript.php
36. Bains MK, Hosseini-Ardehali M (2005) Palatal perforations: past and present. Two case reports and a literature review. British Dental Journal 199(5): 267-269.

37. Lancaster J, Belloso A, Wison CA, McCormick M (2000) Rare case of naso-oral fistula with extensive osteocartilaginous necrosis secondary to cocaine abuse: review of otorhinolaryngological presentations in cocaine addicts. J Laryngol Otol 114(8): 630-633.

38. Egred M, Davis GK (2005) Cocaine and the heart. Postgrad Med J 81(959): 568-571.

39. Cregler LL, Mark H (1986) Medical complications of cocaine abuse. N Engl J Med 315(23): 1495-1500.

40. Gay GR (1982) Clinical management of acute and chronic cocaine poisoning. Ann Emerg Med 11(10): 562-572.

41. Blanksma CJ, Brand HS (2005) Cocaine abuse: orofacial manifestations and implications for dental treatment. Int Dent J 55(6): 365-369.

42. Parry J, Porter S, Scully C, Flint S, Parry MG (1996) Mucosal lesions due to oral cocaine use. Br Dent J 180(12): 462-464.

43. Brown RS, Johnson CD (1994) Corrosion of gold restorations from inhalation of "crack" cocaine. Gen Dent 42(3): 242-246.

44. Johnson CD, Brown RS (1993) How cocaine abuse affects post-extraction bleeding. JADA 124(12): 60-62.

45. Mitchell-Lewis DA, Phelan JA, Kelly RB, Bradley JJ Lamster IB (1994) Identifying oral lesions associated with crack cocaine use. J Am Dent Assoc 125(8): 1104-1108.

46. Goodger NM, Wang J, Pogrel MA (2005) Palatal and nasal necrosis resulting from cocaine misuse. Br Dent J 198(6): 333-334.

47. Yagiela JA (1999) Adverse drug interactions in dental practice: interactions associated with vasoconstrictors. Part V of a series. J Am Dent Assoc 130(5): 701-709.

48. Engel JD (1991) Cocaine: a historical and modern perspective. Nebr Med J 76(8): 263-270.

49. Goldstein FJ (1990) Toxicity of cocaine. Compend Contin Educ Dent 11: 710-716.

50. Lee CY, Mohammedi H, Dixons RA (1991) Medical and dental implications of cocaine abuse. J Oral Maxillofac Surg 49(3): 290-293.

51. Isaacs SO, Martin P, Willoughby JH (1987) 'Crack'(an extra potent form of cocaine) abuse: a problem of the eighties. Oral Surg Oral Med Oral Pathol 63(1): 12-16.

52. Brewer JD, Meves A, Bostwick JM, Hamacher KL, Pittelkow MR (2008) Cocaine abuse: dermatologic manifestations and therapeutic approaches. Journal of the American Academy of Dermatology 59(3): 483-487.

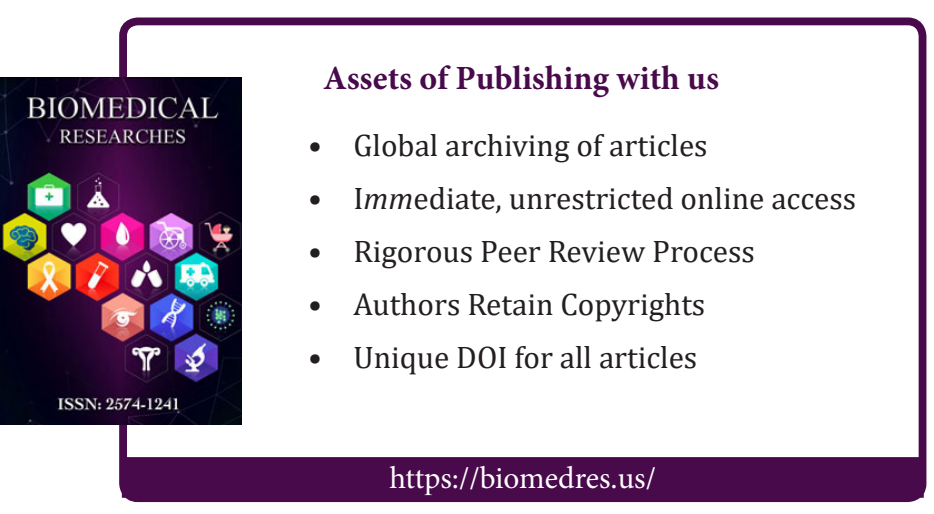

